\title{
Sustancias utilizadas como agente gelificante alternativas al agar en medios de cultivo para propagación in vitro
}

\section{Substances used as gelling agent alternative to the agar in culture media for in vitro propagation}

\author{
Darío Alonso Martin Gordo¹, Oswaldo Cárdenas Gonzalez² y José Constantino Pacheco³ \\ ${ }^{1}$ Químico de Alimentos. ${ }^{2}$ Licenciado en Química y Biología, MSc en Ciencias Químicas, \\ PhD en Ciencias Marinas y ${ }^{3}$ Licenciado en Biología y Química. Especialista en Edafología \\ y Biología Vegetal. MSc y PhD en Ciencias Biológicas.

\begin{abstract}
${ }^{1}$ Universidad Pedagógica y Tecnológica de Colombia, Tunja, Colombia 2Universidad Pedagógica y Tecnológica de Colombia. Facultad de Ciencias. Escuela de Ciencias Químicas. Grupo de investigación Química-Física Molecular y Modelamiento Computacional (QUIMOLUPTC). Tunja. Colombia. ${ }^{3}$ Universidad Pedagógica y Tecnológica de Colombia. Facultad de Ciencias.

Escuela de Ciencias Biológicas. Grupo de investigación Bioplasma UPTC. Tunja. Colombia.
\end{abstract}

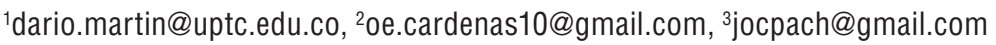

\section{Resumen}

El cultivo de tejidos vegetales comprende un conjunto técnicas ampliamente usadas para propagación vegetal in vitro; sin embargo, una desventaja es el alto costo de componentes utilizados para el medio de cultivo, entre éstos, el agar (solidificante más utilizado), pues la demanda ha elevado su precio. En este artículo se recopilan algunas investigaciones sobre sustancias que se han utilizado como agentes solidificantes alternativos, entre los que se resaltan los almidones (nativos o modificados) y algunas gomas de plantas y exudados bacterianos, que han sido empleados en procesos de organogénesis, embriogénesis y proliferación vegetativa. Los almidones y las gomas reportadas presentaron resultados favorables en el cultivo in vitro de algunas especies vegetales. Se concluye que tanto las gomas como los almidones pueden ser potenciales sustitutos, parciales o totales del agar y logran una disminución de los costos con los almidones, y su posibilidad de modificarse químicamente para mejorar su capacidad gelificante.

Palabras clave: agar, agente gelificante, almidón, gomas, micropropagación

\section{Abstract}

The cultivation of plant fibers is achieved through the implementation of a group of techniques widely used for the propagation of plants in vitro. However, one disadvantage of these techniques is the high cost of components used for the crop's medium, among these, the agar (primary gelling agent), has seen a price increase due to high demand. This article consults several studies regarding substances that have been utilized as alternative gelling agents, among which highlight starches (native or modified) and several plant gums and bacterial excretions that have been used in processes of organogenesis, embryogenesis and vegetative proliferation. The starches and gums studied showed favorable results in the in vitro cultivation of some plant species. The study demonstrates that both gums and starches may be potential substitutes (either partial or total) for agar, achieve a decrease in costs associated with starches, and have an ability to be chemically modified to improve gelling capacity.

Key words: agar, gelling agent, starch, gums, micro-propagation 


\section{Introducción}

Las técnicas de cultivo de tejidos tienen muchas aplicaciones prácticas y comerciales, principalmente en los sectores hortofrutícola, biotecnológico, de producción de especies libres de patógenos y agrícola, y constituyen una alternativa interesante a los métodos tradicionales de propagación, ya que permiten obtener una gran cantidad de material vegetal en un corto período de tiempo (Fasolo \& Predieri, 1988).

A pesar de que las metodologías de cultivo de tejidos vegetales tienen más de cinco décadas desde que fueron desarrolladas, sus beneficios aún no llegan a los agricultores, especialmente a los países más necesitados, lugares donde la mayor parte de la población tiene déficit nutricional por lo que se requiere la optimización de la producción agrícola para mejorar la alimentación y los ingresos del núcleo familiar. El principal problema es la complejidad que presentan algunas de estas tecnologías y el alto costo de su implementación. mayoritariamente ocasionado por el alto precio del agente gelificante, comúnmente agar. Al parecer, la causa del alto precio de este último insumo es su sobrexplotación, consecuencia de una alta demanda, la cual ha hecho que sea cada vez más difícil su obtención, elevando así los precios (Romay et al., 2006 y Mohamed et al., 2010).

Durante los últimos 30 años se han efectuado esfuerzos para buscar sustitutos adecuados para el agar; en consecuencia, un gran número de sustancias han sido probadas por su capacidad de gelificación (Ozel et al., 2008).
Debido a sus propiedades funcionales se ha reportado el uso de almidones y gomas como agentes gelificantes, polímeros naturales como almidones y gomas, que sintetizan las plantas y algunas bacterias. Los almidones están formados por 2 polímeros: la amilosa, compuesta de cadenas lineales de monómeros de D-glucosa unidos por enlaces glicosidicos $\alpha 1-4$, y la amilopectina, compuesta de cadenas con ramificaciones cada 7 o 10 unidades de D-glucosa. La amilopectina posee también enlaces glicosidicos $\alpha 1-4$ en las cadenas lineales y las ramificaciones se unen mediante enlaces $\alpha 1-6$ (Salinas et al., 2003).

En términos generales, los almidones nativos se utilizan ampliamente en la industria alimentaria, ya que son sustancias inocuas capaces de regular y estabilizar la textura de los alimentos y por sus propiedades espesantes y gelificantes. Algunas dispersiones de almidón nativo, como aquellas obtenidas a partir de raíces y tubérculos, producen una textura gomosa y cohesiva en aquellos alimentos donde se utilizan como agentes espesantes (Pacheco de Delahaye \& Techeira, 2009). Todos los almidones tienen los mismos constituyentes (Tabla 1), aunque difieren en el porcentaje de cada uno de ellos, dependiendo de la planta de la cual son extraídos (Daud et al., 2011), por lo cual tienen distintas propiedades funcionales (Hernández et al., 2008).

Por otra parte, las gomas, coloides hidrofílicos (o hidrocoloides), mucílagos, o aún polisacáridos solubles en agua, son algunas denominaciones dadas a las sustancias que tienen la capacidad de formar con agua geles o soluciones viscosas, esto es, que tienen la función de agentes espesantes o gelificantes, estabilizantes de emulsiones (Bobbio y Bobbio, 1992; Dziezak, 1991). 
Tabla 1. Composición química de algunos almidones de distintas fuentes.

\begin{tabular}{lcccccc}
\hline Componentes (\%) & Makal & Camote & Yuca & Sagú & Maíz & Papa \\
\hline Humedad & $(8,99)$ & $(9,83)$ & $(9,48)$ & $(10,5)$ & $(9,9)$ & $(19)$ \\
Proteína cruda & 0,16 & 0,22 & 0,06 & 0,64 & 0,10 & 0,06 \\
Grasa cruda & 0,19 & 0,31 & 0,20 & 0,36 & 0,35 & 0,05 \\
Fibra cruda & 0,35 & 0,28 & 1,01 & 0,06 & 0,62 & NR \\
Cenizas & 0,12 & 0,26 & 0,29 & 0,22 & 0,06 & 0,40 \\
ELN & 99,28 & 98,93 & 98,44 & 98,72 & 98,93 & 99,49 \\
Amilosa & 23,6 & 19,6 & 17,0 & 22,7 & 28,3 & 21,0 \\
Amilopectina & 76,4 & 80,4 & 83,0 & 77,3 & 71,7 & 79,0 \\
\hline
\end{tabular}

Fuente: Hernández et al, 2008

Las gomas pueden ser definidas en términos prácticos como moléculas de alto peso molecular con características hidrofílicas o hidrofóbicas que, usualmente, tienen propiedades coloidales, con capacidad de producir geles al combinarse con el solvente apropiado. Las gomas naturales son polisacáridos altamente hidrofílicos, compuestos de monosacáridos que se unen por enlaces glucosídicos. Se extraen de varios árboles (como exudados) y arbustos o ficocoloides (algas), y se diferencian de las resinas naturales por su composición (tabla 2) y solubilidad. Algunas contienen componentes ácidos y otras son neutras (Pasquel, 2001). Desde hace varios años, se han utilizados gomas, distintas al agar, en algunos productos comerciales tales como Phytagel, Gelrite, Natugel, entre otros, que aprovechan las propiedades funcionales de algunas de estas gomas como sustancias que aumenten la viscosidad y consistencia de los medios de cultivo para propagación vegetal in vitro (Tabla 2).

El presente documento tiene como objetivo la revisión sobre el uso de gomas y almidones en varias técnicas de cultivo de tejidos vegetales in vitro.

\section{Almidones en procesos de organogénesis}

La embriogénesis es un proceso en el que a partir de una célula se generan embriones que pueden producir nuevas plántulas; comprende la embriogénesis cigótica y la embriogénesis somática o adventicia. La embriogénesis somática (asexual o adventicia), consiste en el desarrollo de embriones a partir de células que no son el producto de una fusión gamética, en otras palabras, es un proceso por el cual se produce una estructura bipolar (embrión) a partir de una célula somática, mientras que la embriogénesis cigótica sí es el producto de la fusión gamética (Celestino et al., 2005), mientras que el proceso involucrado en la transformación de una célula a una planta u órgano se denomina organogénesis. Cuando la regeneración de la plántula se realiza sin la formación de callo, se denomina organogénesis directa; primero se forman células no diferenciadas o callo y, posteriormente, se diferencian y forman una planta, se conoce como organogénesis indirecta (Calva y Pérez, 2005). 
Tabla 2. Algunas gomas utilizadas como agentes gelificantes en medios de cultivo de propagación in-vitro.

\begin{tabular}{|c|c|c|}
\hline GOMA & COMPOSICIÓN QUÍMICA & FUENTE \\
\hline Guar & $\begin{array}{c}\text { Galactosa (unida por } \alpha 1-6 \text { ) y manosa } \\
\text { ( unidas por } \beta 1-4 \text { ) }\end{array}$ & Cyamopsis tetragonolobus \\
\hline cassia & $\begin{array}{c}\text { Galactosa (unida por } \alpha 1-6 \text { ) y manosa } \\
\text { ( unidas por } \beta 1-4 \text { ) }\end{array}$ & endospermo de Sennao btusifolia \\
\hline xantana & $\begin{array}{c}\text { cadena de D-glucopiranosilo unido enlace } \\
\beta \text { 1-4. Ramificación de trisacáridos de } \\
\text { D-manopiranosilo y de ácido } \\
\text { D-glucopiranosilurónico }\end{array}$ & $\begin{array}{l}\text { Exudado de la bacteria } \\
\text { Xanthomonas campestris B-1459 }\end{array}$ \\
\hline Agar & $\begin{array}{c}\text { Agarosa (galactosa) y agaropectina (anhi- } \\
\text { drogalactosa parcialmente esterificada } \\
\text { con ácido sulfúrico) }\end{array}$ & $\begin{array}{c}\text { Gelidium cartilagineum, Gracilaria } \\
\text { confervoides y Pteroclaia } \\
\text { capillacea }\end{array}$ \\
\hline $\begin{array}{l}\text { Gellan (gelrite y } \\
\text { phytagel) }\end{array}$ & $\begin{array}{c}\text { tetrasacárido, que consiste en dos resi- } \\
\text { duos de D- glucosa y uno de cada uno de } \\
\text { los residuos de L- ramnosa y } \\
\text { D- ácido glucurónico }\end{array}$ & $\begin{array}{l}\text { Exudado de la bacteria } \\
\text { Pseudomonas elodea }\end{array}$ \\
\hline Goma katira & $\begin{array}{l}\text { D-galactosa, acido D-galacturonico y } \\
\text { L-ramnosa en proporción molar } 2: 1: 3\end{array}$ & $\begin{array}{l}\text { exudado de Cochlospermum } \\
\text { religiosum }\end{array}$ \\
\hline natugel & $-{ }^{*}$ & Kappaphycu salvarezii \\
\hline
\end{tabular}

Fuente: recopilación de los autores. -* no reportado en la literatura.

Algunos almidones han sido utilizados como gelificantes en medios de cultivo para organogénesis de plantas. Daud et al. (2011 a y 2011 b) cultivaron segmentos de tallos de Celosia sp. en medios de cultivo con la mitad de concentración de los componentes del medio Murashige y Skoog (1962) y otro sin tales suplementos, gelificados con harina de yuca, harina de arroz, harina de maíz y almidón de papa. No se encontraron diferencias significativas en la regeneración por vía de organogénesis directa en ninguno de los solidificantes probados.

En un estudio realizado en Irán, se probaron un medio líquido con sustrato de algodón y diferentes combinaciones de almidón, sémola o harina, polvo de patata y agar en dos etapas de la micropropagación (inducción de brotes y proliferación) de violeta africana (Saintpaulia ionantha) (tabla 3). La mayor frecuencia de regeneración se encontró en medios que contienen agar $(0,8 \%)$, combinación de almidón: sémola, polvo de patata $(2: 1: 1)$ en 9 y el $12 \%$ y la combinación de almidón (6\%) más agar $(0,4 \%)$, pero el máximo número brotes se produjeron en medios que contenían agar $(0,8 \%)$, combinación de almidón $(6 \%)$ más agar $(0,4 \%)$ y medio líquido con sustrato de algodón. La mejor proliferación de brotes tuvo lugar en medio líquido con sustrato de algodón. Los resultados mostraron que la combinación de almidón: sémola, polvo de patata (2:1:1) en $9 \%$ y almidón $(6 \%)$ más de agar $(0,4 \%)$ pueden ser alternativas, para sustituir al almidón, adecuadas en etapa de regeneración, pero el número de brotes es menor que en medios gelificados con solo agar (Sharifi et al., 2011). 
Tabla 3. Combinaciones de agentes gelificantes en medios de cultivo para propagación de violeta africana (S. ionantha)

\begin{tabular}{cl}
\hline Medio & \multicolumn{1}{c}{ Composición } \\
\hline A & 12\% (almidón 2: harina 1:polvo de papa 1) \\
\hline B & $9 \%$ (almidón 2: harina 1:polvo de papa 1) \\
\hline C & $9 \%$ (almidón 1: harina 1:polvo de papa 1) \\
\hline D & $6 \%$ (almidón 2: harina 1:polvo de papa 1) \\
\hline E & $6 \%$ (almidón 1: harina 1:polvo de papa 1) \\
\hline F & $6 \%$ (almidón 2: harina 1:polvo de papa 1) $+2 \mathrm{~g} / \mathrm{L}$ agar \\
\hline G & $6 \%$ (almidón 1: harina 1:polvo de papa 1) $+2 \mathrm{~g} / \mathrm{L}$ agar \\
H & $6 \%$ (almidón 2: harina 1:polvo de papa 1) $+4 \mathrm{~g} / \mathrm{L}$ agar \\
\hline I & $3 \%$ (almidón 2: harina 1:polvo de papa 1) $+4 \mathrm{~g} / \mathrm{L}$ agar \\
J & $3 \%$ (almidón 1: harina 1:polvo de papa 1) $+4 \mathrm{~g} / \mathrm{L}$ agar \\
\hline K & $9 \%$ almidón \\
L & $6 \%$ almidón $+4 \mathrm{~g} / \mathrm{L}$ agar \\
\hline M & $3 \%$ almidón $+4 \mathrm{~g} / \mathrm{L}$ agar \\
N & $9 \mathrm{~g} / \mathrm{L}$ agar \\
\hline O & medio liquido con sustrato de algodón \\
\hline &
\end{tabular}

Fuente: Sharifi et al, 2010.

\section{Almidones en procesos de embriogénesis}

El almidón de arroz y la fécula o harina de maíz, han sido probados como agentes gelificantes en micropropagación. Se reporta el cultivo de embriones cigóticos de cacao (Theobroma cacao L.) en medios de cultivo gelificados con almidón de arroz y maicena, en concentraciones desde 4 hasta $8 \%$ en ambos casos, comparados con un testigo de agar en concentración de $0.8 \%$. Gonzales y Silva (1999) encontraron que estos medios gelificados con almidón de arroz y maicena, en concentraciones bajas (4-6\%) se oscurecían, por acción de fenoles provenientes del embrión cigótico, mientras que en concentraciones más elevadas, no se presentó tal comportamiento. Además, en el cultivo aséptico de embriones cigóticos de cacao se puede emplear el almidón de arroz y la maicena en sustitución del agar, obteniéndose los mejores resultados, en cuanto a longitud de raíces, en el primer caso a concentraciones del $8 \%$, y en el segundo caso del 5 y $8 \%$, respectivamente.

Almidones en procesos de micropropagación o proliferación

Hay reportes sobre la utilización de almidones de distintas fuentes, como agentes gelificantes en medios de cultivo para proliferación vegetal. Se ha micropropagado segmentos nodales de papa (Solanum tuberosum) en medios gelificados con 
almidón de yuca (Kuria et al., 2008), sagú (Naik y Sarkar, 2001); banana (Musa) en medios con almidón de papa y yuca (Kodyn y Zapata, 2001); manzana (Malus domestica Borkh) en medios solidificados con almidón de maíz (Zimmerman et al., 1995).

En un estudio hecho por Romay y colaboradores (2006) se sugiere la utilización de almidones modificados de yuca como sustitutos del agar. En el estudio cultivaron micro-esquejes de yuca (Mahinot esculenta Crantz) en medios solidificados con tres almidones modificados comparados con un blanco de Phytagel. De igual manera, analizaron el número de nudos y raíces para todos los tratamientos, y peso seco y húmedo para el mejor tratamiento con almidón y el blanco de Phytagel y encontraron diferencias significativas en los tratamientos AIM TF-352 y AIM TP-212 con respecto al control, pues disminuyeron el número de nudos y raíces. mientras el AIM TF-351 no. En el estudio se concluyó que el almidón AIM TF-351 no tuvo efectos significativos en ninguna de las variables analizadas y, por tanto, puede ser un sustituto del agar.

Mbanaso (2008) estudió el efecto de subcultivos consecutivos de 2 genotipos de Musa, cultivados en medios solidificados con almidón de yuca (cassava). No se encontraron diferencias significativas con el testigo de agar, en cuanto al porcentaje de brotes producidos, mientras que sí se presentaron diferencias en la robustez de las plántulas, mayoritariamente en los medios de cultivo con mayor concentración de almidón, posiblemente porque aumentaba la dureza del medio, lo que impidió la difusión de los nutrientes. También afectó la absorción de agua y algunos nutrientes que potenciaban la dureza de las plántulas. Pero al igual que Romay et al., recomendó el almidón de yuca (cassava) como sustituto más económico del agar.

La harina de yuca es rica en almidón; por tal razón, se ha utilizado como agente gelificante mezclada con agar o adicionada sola. Maliro y Lameck (2004) cultivaron plántulas de F. albida y Uapaca kirkiana. Encontraron que en las 2 primeras semanas no se presentaban diferencias significativas en número de brotes generados y altura de las plántulas en ninguna de las especies estudiadas, pero en las semanas $4^{\underline{a}}$ y $5^{\underline{a}}$ de incubación, se observaron resultados estadísticamente significativos. Los medios preparados solo con harina de yuca, después de 5 semanas perdieron la consistencia, lo que afectó el crecimiento y peso de los explantes en ambas especies.

La micropropagación de nodos de papa (Solanum tuberosum) se realizó en medio MS (Murashige y Skoog, 1962) gelificado con mezclas de agar-almidón de maíz (CS) y agar-almidón de papa (PS). Mohamed et al. (2010) no encontraron diferencias significativas en la altura de las plántulas, pero si un aumento significativo en el número de brotes/ explante. El aumento más notable se encontró en medios solidificados con $60 \mathrm{~g} / \mathrm{L}$ de PS $+1 \mathrm{~g} / \mathrm{L}$ de agar. Las plántulas desarrolladas en los medios de cultivo con $40 \mathrm{~g} / \mathrm{L}$ de CS o PS tuvieron un mayor peso fresco y seco en comparación con los del control de agar. El medio con $50,60 \mathrm{~g} / \mathrm{L}$ de PS o $60 \mathrm{~g} / \mathrm{L}$ de CS y $50 \mathrm{~g} / \mathrm{L}$ de agar a CS + 1g/L aumentaron significativamente el porcentaje de peso seco. Se sugiere que la utilización de agar en bajas concentraciones mezclado con almidón de papa o de maíz puede disminuir los costos de los medios de cultivo para micropropagación invitro (Mohamed et al., 2010).

Rodríguez y Hechevarría (2006), cultivaron segmentos nodales de Orthosiphon aristatus Blumey Artemisia absinthium L., dos especies de plantas altamente demandadas por sus propiedades medicinales. Utilizaron harina de sagú (Maranta arundinacea L.) y un gel de Aloe vera (L.) N.L. Burm como solidificantes del medio de Murashige y Skoog (1962). Los resultados mostraron que medios solidificados con $0,8 \%(\mathrm{p} / \mathrm{v})$ de agar (tratamiento 1$), 0,4 \%$ $(\mathrm{p} / \mathrm{v})$ de agar más $0,4 \%(\mathrm{p} / \mathrm{v})$ de harina de sagú 
(tratamiento 2$), 0,4 \%(\mathrm{p} / \mathrm{v})$ de más $15 \%(\mathrm{p} / \mathrm{v})$ de gel de $A$. vera (tratamiento 3 ) y $0,8 \%(p / v)$ de harina de sagú más $15 \%(\mathrm{p} / \mathrm{v})$ de gel de $A$. vera (tratamiento 4) no arrojaron diferencias significativas en los índices de crecimiento vegetativo (altura, número de hojas y raíces) en ninguna de las dos especies cultivadas. Sin embargo, el tratamiento 4 presentó los mejores resultados en $O$. aristatus, mientras el tratamiento 2 lo fue para medios sembrados con $A$. absinthium.

En un estudio reciente realizado en Etiopía se evaluó la eficiencia del almidón de ensete (buIla) como agente gelificante alternativo para la micropropagación de Vanilla planifolia. Los resultados revelaron que el número de brotes y de peso fresco se mejoraron significativamente en los medios de multiplicación gelificados con buIla (8\%). A pesar de todos los brotes producidos tuvieron un enraizamiento del $100 \%$, se obtuvo un mayor crecimiento de los brotes en medios suplementados con bulla ( $8 \%),(10 \%)$ y agar. La sustitución de agar por bulla (8\%) podría ahorrar alrededor de $72,5 \%$ del costo de agar. Un inconveniente detectado en los ensayos fue la opacidad de los medios, que dificulta la observación de contaminación temprana (Mengesha et al., 2012).

La elaboración de medios de cultivo para micropropagación, sustituyendo parcial o totalmente el agar por almidones, es una opción rentable, que disminuye los costos, debido a que los tubérculos o cereales de donde se extraen, se encuentran en mayor cantidad, comparado con las algas rojas (Rhodophyceae) de donde se extrae el agar. El inconveniente de los almidones es la menor fuerza gelificante, pero puede ser resuelto agregando agar en bajas concentraciones, o aumentando la cantidad de almidón en el medio. También se pueden utilizar modificaciones químicas para mejorar las propiedades funcionales de los almidones, con el fin de incrementar el poder solidificante (Kuria et al., 2008).

\section{Gomas}

\section{Gomas como gelificantes en procesos de organogénesis}

En un estudio de regeneración de brotes en segmentos foliares de tabaco (Nicotiana tabacum L.), realizado por Ozel et al., (2008), se evaluó el efecto de los medios de cultivo gelificados con 7 a $1 \mathrm{~g} / \mathrm{L}$ de agar y 0-6 isubgol g/L; 2,25 a 0,25 g/L Gelrite y 0-6 g / I isubgol; 5,25 a 0,25 g/L Phytagel y 0-5 g $/ \mathrm{L}$ isubgol, y $1-15 \mathrm{~g} / \mathrm{L}$ isubgol. Los resultados demostraron que, independiente de algunos problemas con los geles, el isubgol $(7 \mathrm{~g} / \mathrm{L})$ indujo un mayor número de brotes y de raíces; además, la longitud de los brotes fue mayor en medios gelificados con isubgol en concentración de $9 \mathrm{~g} / \mathrm{L}$. Para una cantidad determinada de medio de cultivo, las mezclas de agar-isubgol, Gelrite-isubgol son más baratas. Así mismo, las mezclas de agar-isubgol, Gelriteisubgol gelificaron a bajas temperaturas, propicias para el uso seguro de estos geles cuando se emplean sustancias lábiles, en la transformación genética o experimentos de cultivo de tejidos.

En procesos de germinación y de organogénesis indirecta en hojas de arroz (Oryza sativa L.) realizados por Afrasiab y Rabia (2011), se utilizó phytagel como agente gelificante del MS (Murashige y Skoog 1962) y LS (Linsmaier y Skoog 1965). Los resultados demostraron que a pesar de que el porcentaje de germinación, la inducción de callo, y los índices de crecimiento evaluados fueron menores en los medios gelificados con phytagel, este gelificante es una alternativa al empleo de agar, pues contiene menos impurezas y el $\mathrm{pH}$ del medio es más estable a través del tiempo de cultivo.

Saglam y Cifici (2010) utilizaron isubgol como agente gelificante en medios para organogénesis indirecta en hojas de Woad (Isatis tinctoria), comparados con un blanco de agar. Encontraron mejor respuesta callogénica y de diferenciación en los medios solidificados con isubgol. 
Gomas como solidificantes en procesos de embriogénesis

Jain-Raina y Babbar (2011) utilizaron mezclas de varios agentes gelificantes goma guar $(2,6$ a $2,9 \%)+\operatorname{Agar}(0,1-0,4 \%)$; goma xantana $(0,6-0,9 \%)$ + Agar (0,1-0,4\%); Isubgol (2,6 a 2,9\%) + Agar (0,1$0,4 \%)$; goma guar (1,5 a 2,9\%) + goma xantana (0,1-1,5\%); Isubgol (1,6 a 2,9\%) + goma xantana $(0,1-1,4 \%)$ y goma guar $(2,6$ a $2,9 \%)+$ Agar $(0,1-$ $0,4 \%)$. La concentración total de los agentes gelificantes mezclados con goma xantana fue $1 \%$, mientras que en los demás fue $3 \%$. Utilizaron estos medios para geminar e inducir embriogénesis somática en Albizzia lebbeck.
En los resultados encontrados fue evidente que la respuesta morfogénica fue apoyada por toda la mezcla de gelificación, en la mezcla que contenía 2,6\% isubgol y $0,4 \%$ de agar. El porcentaje de germinación de semillas mejoró significativamente cuando el agar se mezcló con goma xantana o goma guar, ya que cuando se utilizaron solas, los resultados no fueron tan exitosos (tabla 4). La otra característica común es la reducción en la respuesta callogénica con un aumento de agar al 0,4\% en mezclas de gelificación con la goma de guar e isubgol. Jain-Raina y Babbar concluyeron que las mezclas de goma xantana y guar, con agar, pueden ser sustitutos en los medios de cultivo, como agente gelificante, lo que disminuyo costos y mejoró resultados de crecimiento en las plántulas.

Tabla 4. Índices de crecimiento evaluados en explantes de A. lebbeck inoculados en medios modificados.

\begin{tabular}{|c|c|c|c|c|}
\hline $\begin{array}{c}\text { Agente } \\
\text { gelificantes }\end{array}$ & $\begin{array}{c}\text { No. } \\
\text { Explantes }\end{array}$ & $\begin{array}{c}\text { Germinación } \\
(\%)\end{array}$ & $\begin{array}{c}\text { Altura } \\
\text { brotes (cm) }\end{array}$ & $\begin{array}{l}\text { Longitud } \\
\text { raíces }(\mathrm{cm})\end{array}$ \\
\hline $0,9 \% \mathrm{Ag}$ & 96 & $82,2^{\mathrm{a}}$ & $7,77 \pm 3,45 b c$ & $5,40 \pm 2,90 b c$ \\
\hline $3 \% \mathrm{GG}$ & 92 & $47,9 b$ & $5,37 \pm 2,72 c$ & $4,33 \pm 2,25 c$ \\
\hline $2,9 \% \mathrm{GG}+0,1 \% \mathrm{Ag}$ & 96 & $81,2^{\underline{a}}$ & $8,57 \pm 2,98 a b$ & $5,98 \pm 1,97 b c$ \\
\hline $2,8 \% \mathrm{GG}+0,2 \% \mathrm{Ag}$ & 96 & $73,9^{a}$ & $9,21 \pm 3,04 a b$ & $6,77 \pm 2,46 a b$ \\
\hline $2,7 \% \mathrm{GG}+0,3 \% \mathrm{Ag}$ & 96 & $80,2 a$ & $8,66 \pm 2,63 a b$ & $5,83 \pm 2,50 b c$ \\
\hline $2,6 \% \mathrm{GG}+0,4 \% \mathrm{Ag}$ & 96 & $85,4 a$ & $10,70 \pm 1,30 a$ & $8,03 \pm 2,13 a$ \\
\hline $1 \%$ Xan & 96 & $52,0 b$ & $6,10 \pm 1,92 \mathrm{c}$ & $4,05 \pm 1,76 \mathrm{c}$ \\
\hline 0,9 Xan $+0,1 \% \mathrm{Ag}$ & 96 & $71,8 a$ & $8,21 \pm 2,88 b$ & $6,57 \pm 2,55 a b$ \\
\hline 0,8 Xan $+0,2 \% \mathrm{Ag}$ & 96 & $86,4 a$ & $8,08 \pm 2,42 b$ & $5,52 \pm 2,31 b c$ \\
\hline 0,7 Xan $+0,3 \% \mathrm{Ag}$ & 96 & $76,0 a$ & $8,27 \pm 2,12 b$ & $5,61 \pm 2,44 b c$ \\
\hline $0,6 \%$ Xan $+0,4 \% \mathrm{Ag}$ & 96 & $89,5 a$ & $9,09 \pm 2,97 a b$ & $7,24 \pm 2,52 a b$ \\
\hline $3 \%$ Is & 96 & $83,3 a$ & $10,00 \pm 2,97 a b$ & $6,61 \pm 2,68 a b$ \\
\hline $2,9 \%$ Is $+0,1 \% \mathrm{Ag}$ & 96 & $81,2 a$ & $9,79 \pm 2,34 a b$ & $5,51 \pm 2,53 b c$ \\
\hline $2,8 \%$ Is $+0,2 \% \mathrm{Ag}$ & 96 & $86,4 a$ & $10,79 \pm 1,96 a$ & $5,62 \pm 1,82 b c$ \\
\hline $2,7 \%$ Is $+0,3 \% \mathrm{Ag}$ & 96 & $87,5 a$ & $10,66 \pm 2,20 a$ & $6,39 \pm 1,79 b$ \\
\hline $2,6 \%$ Is $+0,4 \% A g$ & 96 & $82,1 a$ & $10,56 \pm 1,85 a$ & $6,71 \pm 1,59 a b$ \\
\hline
\end{tabular}

Ag: agar GG: goma guar Xan: gomaxantanals: isubgol

Fuente: Jain-Raina Y Babbar (2011). 
Van Ark et al. (1991) no obtuvieron diferencias estadísticas en los resultados obtenidos, empleando medios de cultivo gelificados con agar y gelrite en procesos de embriogénesis somática indirecta en Poa pratensis L.

Saglam y Cifici (2010) utilizando isubgol como agente gelificante en medios para embriogénesis de hipocótilos de Woad (Isatis tinctoria), comparados con un blanco de agar, encontraron mejor respuesta en los medios solidificados con agar. Moon et al. (2004) reportaron la siembra de proembriones somáticos de Ceratozamia hildae en medios gelificados con phytagar, Gel-Ro, Agar TC, agargel y consideraron mejor gelificante el agente de prueba al Gel-Ro.

Jain-Raina y Babbar en 2002 utilizaron la goma katira como agente gelificante en medios para inducir embriogénesis somática en $A$. labbeck. No encontraron diferencias significativas con el tratamiento control gelificado con agar. Posteriormente, en 2006 estudiaron el efecto de la goma xantana como agente gelificante en medios para inducir embriogénesis somática indirecta de Calliandra tweedii, encontrando mejores resultados en los medios en los que la concentración de goma xantana fue del $1 \%$, en variables como respuesta callogénica y porcentaje de germinación. Babbar et al. (2005) encontraron diferencias significativas en el número de embriones formados de $C$. tweedii y el porcentaje de germinación de semillas de $\mathrm{Li}$ num usitatissimum, con goma guar y agar como agente solidificante de los medios utilizados.

\section{Gomas en procesos de micropropagación} o proliferación

En ensayos de micropropagación de brotes de manzano (Malus prunifolia Borkh) realizados por Lucyszyn et al. (2005) en medios de cultivo gelificados con mezclas de goma guar-agar y goma cassia-agar en proporción $3 / 3 \mathrm{~g} / \mathrm{L}$, comparadas con un testigo de agar de $6 \mathrm{~g} / \mathrm{L}$, los resultados obtenidos indicaron una mayor proliferación de los brotes de manzano, así como una menor aparición de brotes hiperhidratados en los medios de cultivo gelificados con gomas y agar. Las mezclas utilizadas para sustituir al agar no afectaron significativamente índices de crecimiento como cantidad y longitud de los brotes regenerados.

Posteriormente, Lucyszyn et al. (2006) también probaron la eficacia de la sustitución parcial de agar por galactomananos (GMS), obtenidos a partir de diferentes fuentes. Se ensayó la micropropagación de fresa (Fragaria $x$ ananassa Duchesne) en los medios modificados. Las gomas guar y cassia se mezclaron con agar en la proporción de 0.3/0.3\% (w / v) en medio MS (año), y el rendimiento se comparó con comportamiento de medio de agar que contenía sólo $(0,6 \%, w / v)$ como agente gelificante. Los resultados obtenidos indicaron que el agar puede ser parcialmente remplazado por galactomananos, puesto que las mediciones reológicas confirmaron una buena interacción entre los polisacáridos. También se observaron un mejor rendimiento y mayor proliferación de brotes de fresa; se evidenció que las raíces fueron más largas en los medios modificados. Así, el comportamiento del gel de galactomananos y la rentabilidad comercial, que es menor para el medio modificado en comparación con el sistema solidificado con agar, mostró el uso potencial de estos galactomananos para su aplicación en cultivo de tejidos vegetales.

Chacón et al. (2000), utilizaron Phytagel para solidificar medios de cultivo para la propagación invitro de yampi (Dioscorea trífida) y ñame (Dioscorea alata). Ellos utilizaron un blanco que fue gelificado con agar, para comparar el comportamiento de los índices de crecimiento. Encontraron diferencias significativas en ambas especies entre los resultados obtenidos en altura, peso fresco y peso seco, que fueron superiores cuando los medios se gelificaron con phytagel, y porcentaje de materia seca obtenidos en los medios en donde se utilizó agar como solidificante. Además reportaron que al aumentar la concentración de agente gelificante, por encima del valor que confirió una consistencia óptima en los medios, los índices de crecimiento se afectaron negativamente, pues una 
mayor consistencia y dureza de los medios impide la mejor absorción y movilidad de los nutrientes dentro de estos.

Capote Rodríguez et al. (2002) evaluaron el efecto de un agente gelificante cubano, Natugel, en el crecimiento de cultivos in vitro de plántulas de tomate (Solanum lycopersicum L.) de la variedad Cuba C-2781. Utilizaron como explantes ápices y nudos cultivados in vitro en medio MS con sacarosa, y Natugel en dos formulaciones: I y II que se diferenciaron en la granulometría y en la densidad aparente. Compararon con cultivos control en las mismas condiciones anteriores pero con la adición de agar en sustitución del agente gelificante. La respuesta de los cultivos se evaluó en función del número de nudos y la altura de las plántulas en sucesivos subcultivos y no se encontraron diferencias significativas entre la respuesta obtenida en medio solidificado con agar y la obtenida en medio solidificado con la mezcla Natugel I/II.

Aunque se ha hecho ya un recuento de las sustancias que han sido utilizadas como agentes gelificantes alternativos, lo más importante es conocer el costo que tiene cada una de estas. En la tabla 5 se muestra una relación de las sustancias utilizadas, haciendo énfasis en las concentraciones empleadas, así como su costo. Se observa que el agar es el gelificante, que a pesar de que se usa en baja concentración, es el que más eleva el costo de un litro de medio de cultivo.
De acuerdo con los costos mostrados en la tabla 5 se recomienda como agentes gelificantes la goma guar y los almidones de papa y yuca, pues con ellos se han hecho un mayor número de investigaciones y se han cultivado una mayor cantidad de especies vegetales. En el caso colombiano, los almidones de papa, yuca y maíz son de fácil adquisición, pues el país produce estas materias primas de forma permanente. Las gomas son más caras que los almidones, pero al usarse en cantidades menores, tienen un precio equivalente por litro.

Los mejores resultados, ya sean fisiológicos y físicos, se han reportado con las mezclas entre agentes gelificantes, como mezclas de agar con algunas gomas y almidones. Estas mezclas presentan una menor disminución en el costo de los medios de cultivo, pero pueden ser más eficientes que los agentes alternativos. Con el uso de almidones y gomas como gelificantes se obtienes reducciones aproximadas desde el $30 \%$ al $70 \%$ en los costos, basados en el precio del solidificante, lo que permite una alternativa válida económicamente para implementar estas técnicas, así como la oportunidad de mejorar los mercados de productos como la papa, yuca, arroz, que tendrían una nueva línea de comercio, como materia prima para extracción de almidones, ayudando al sector agrícola colombiano. 
Tabla 5. Relación de sustancias utilizadas como agentes gelificantes.

\begin{tabular}{|c|c|c|c|c|}
\hline Sustancia & $\begin{array}{c}\text { Concentracion } \\
(\mathrm{g} / \mathrm{l})\end{array}$ & $\begin{array}{l}\text { Especie } \\
\text { cultivada }\end{array}$ & $\begin{array}{l}\text { Costo } \\
\text { kg sustancia } \\
(\operatorname{co\$ })\end{array}$ & $\begin{array}{c}\text { Costo } \\
\text { solidificante } \\
\text { por litro (co\$) }\end{array}$ \\
\hline \multirow{3}{*}{ Almidón de yuca } & 100 & $\begin{array}{l}\text { S. tuberosum L. (MP) } \\
\text { M. esculenta (MP) }\end{array}$ & & 936.6 \\
\hline & $60-70$ & $\begin{array}{l}\text { Musa (MP) } \\
\text { U. kirkiana (MP) }\end{array}$ & 9326 & $560-653$ \\
\hline & 80 & Celosia sp (OR) & & 746.08 \\
\hline Almidón de sagú & 80 & S.tuberosum L. (MP) & 7000 & 560 \\
\hline Almidón de maiz & $\begin{array}{c}60 \\
40-80\end{array}$ & $\begin{array}{l}\text { S. tuberosum L. (MP) } \\
\text { Celosia sp (OR) }\end{array}$ & 5686,44 & $\begin{array}{c}341,1864 \\
227,45-454,92\end{array}$ \\
\hline Almidón de papa & $\begin{array}{c}60-80 \\
90\end{array}$ & $\begin{array}{c}\text { Musa (MP) } \\
\text { Celosia sp (OR) } \\
\text { S. ionantha (OR) }\end{array}$ & 14000 & $\begin{array}{c}840-1120 \\
1260\end{array}$ \\
\hline Almidón de arroz & $40-80$ & T.cacao L. (EC) & 15400 & $616-1232$ \\
\hline Almidón de ensete & 80 y 100 & V. planifolia (MP) & 5980 & $478,4-598$ \\
\hline Goma karaya & 30 & Citrus jambhiri Lush. (MP) & 16608 & 498,24 \\
\hline \multirow{3}{*}{ Phytagel } & 20 & M. domestica Borkh (MP) & & 10354,62 \\
\hline & 25 & $\begin{array}{c}\text { Robinia pseudoacacia (MP) } \\
\text { D. trifida y D. alata (MP) }\end{array}$ & 517731 & 12943,275 \\
\hline & 1,$3 ; 1,8 ; 2,3$ & O. sativa L. (OR) & & $673,05-1190,78$ \\
\hline \multirow{3}{*}{$\begin{array}{l}\text { Goma gellan } \\
\text { (Gelrite) }\end{array}$} & 2,4 & C. hildae (ES) & & $\begin{array}{l}750,1824 \\
2500,608\end{array}$ \\
\hline & 8 & P. pratensis L. (ES) & 312576 & \\
\hline & 3,4 & $\begin{array}{l}\text { Aloe polyphylla (MP) } \\
\text { S. Yoshimurae (MP) }\end{array}$ & & 1062,7584 \\
\hline \multirow{4}{*}{ Goma guar } & 20 & $\begin{array}{c}\text { C. tweedii (ES) } \\
\text { Crataeva nurvala (MP) }\end{array}$ & & 843,18 \\
\hline & 10 & $\begin{array}{l}\text { Chlorophytum borivilianum } \\
\text { (MP) }\end{array}$ & 42159 & 421,59 \\
\hline & 30 & A. Labbeck (ES) & & 1264,77 \\
\hline & 40 & L. usitatissimum (EC) & & 1686,36 \\
\hline Goma katira & 30 & S. cuminii & 70400 & 2112 \\
\hline Goma cassia/agar & 30 & $\begin{array}{c}\text { P. communis L. } \\
\text { cv.Durondeau (MP) } \\
\text { F. ananassa Duchesne (MP) }\end{array}$ & 54550 & 1636,5 \\
\hline Goma xantana & 10 & $\begin{array}{l}\text { C. tweedii (ES) } \\
\text { A. labbeck (ES) }\end{array}$ & 34998 & 349,98 \\
\hline \multirow{3}{*}{ Isubgol } & 7 & N. tabacum L. (OR) & $47000-68000$ & 402,5 \\
\hline & 15 & I. tinctoria (ES) (MP) & & 862,5 \\
\hline & 30 & A. labbeck (ES) & & 1725 \\
\hline Agar agar & $6-9$ & Todas las anteriores & $\begin{array}{l}487664- \\
585600\end{array}$ & $2925-4515$ \\
\hline
\end{tabular}

ES: embriogénesis somática MP: micropropagación ～OR: organogénesis CO\$: pesos colombianos 


\section{Conclusiones}

El avance de las investigaciones enfocadas a la sustitución parcial o total del agar como agente gelificante en los medios de cultivo in vitro para propagación, ha arrojado resultados prometedores, principalmente en lo que respecta al uso de almidones, ya que, aunque algunos resultados con gomas como solidificantes son muy buenos, los almidones tienen un menor costo y son de fácil adquisición y extracción; además, pueden ser modificados para conferir propiedades funcionales específicas, que les permitan ser utilizados con mayor eficiencia en micropropagación vegetal in vitro, ya sea como único agente gelificante, o mezclado con agar u otro tipo de goma.

La implementación de almidones o gomas como agentes gelificantes alternativos reporta una disminución en los costos de los medios de cultivo para tejido in vitro de hasta el $70 \%$ comparados con los del agar, aunque fisiológicamente hablando los mejores resultados se obtienen en las sustituciones parciales que se han estudiado.

\section{Agradecimientos}

La investigación fue posible gracias a la colaboración de los grupos de investigación BIOPLASMAUPTC y QUIMOL, de la Universidad Pedagógica y Tecnológica de Colombia UPTC, sede central.

\section{Literatura citada}

1. Afrasiab, H. \& Jafar, R. (2011). Effect of different media and solidifying agents on callogenesis and plant regeneration from different explants of rice (Oryza sativa L) varieties super basmati and IRRI-6.PakistanJournal of Botany 43(1), 487-501.

2. Agrawal, A., Sanayaima, R., Tandon, R. \& Tyagi, R. K. (2010). Cost-effective in vitro conservation of banana using alternatives of gelling agent (isabgol) and carbon source (market sugar). Acta Physiol Plant 32, 703-711.
3. Atici, T., Mahmood Khawar, K., Ozel, C. A., Katircioglu, H., \& Alev Ates, M. (2008). Use of psyllium (isubgol) husk as an alternative gelling agent for the culture of prokaryotic microalgae (Cyanobacteria) Chroococcu slimneticus Lemmermann and eukaryotic green microalgae (Chlorophyta) Scenedesmus quadricauda (Turpin) Brebisson. African Journal of Biotechnology 7 (8), 1163-1167.

4. Babbar, S. B., Jain, r., walia, A. (2005). Guar gum as a gelling agent for plant tissue culture media. In Vitro Cellular \& Development Biology Plant 41, 258-261.

5. Bobbio P.A.; Bobbio, F.O. (1992). Química do processamento de alimentos. (2 ${ }^{2}$ Edicion). São Paulo: Livraria Varela.

6. Calva, G. y Pérez, J. (2005). Cultivo de células y tejidos vegetales: fuente de alimentos para el futuro. Revista Digital Universitaria 6 (11). 1-16.

7. Capote, A., Álvarez, F., Fundora, Z., Rodríguez S., Pérez, O. \& Fonseca, D. (2002). Evaluación de un agente gelificante cubano, Natugel, en el cultivo in vitro de plántulas de tomate. Biotecnología Aplicada 19, 37-40.

8. Celestino, C., Hernández, I., Carneros, E., López-Vela D. \& Toribio, M. (2005). La embriogénesis somática como elemento central de la biotecnología forestal. Investigación Agraria: Sistemas de Recursos Forestales 14(3), 345-357.

9. Chacón, A., G. Saborío, F., Gómez, L., Torres, S. \& Valverde, R. (2000). El tipo de gelificante en el desarrollo in-vitro y la aclimatización de plantas de yampi (Dioscorea trífida) y ñame (Dioscorea alata). Agronomía costarricense 24 (002), 57-64.

10. Daud, N., Mat Tal, R., Mohd Noor, N. N. \& Alimon, H. (2011a). Potential of alternative gelling agents in media for the in vitro micro-propagation of Celosia sp. Internacional Journal of Botany 7(2), 183-188.

11. Daud, N., Mat Tal, R., Mohd Noor, N. N. \& Alimon, H. (2011b). Provision of low cost media options for in vitro culture of Celosia sp. African Journal of Biotechnology 10(80), 18349-18355.

12. Dobranszki, J., Magyar-Tabori, K. \& Tombacz, E. (2011). Comparison of the rheological and diffusion properties of some gelling agents and blends and their effects on shoot multiplication. Plant Biotechnology Reproduction 5, 345-352.

13. Dziezak J.D. (1991). A focus on gums. Food Technology 45(3), 115

14. Fasolo, F.M. \& Predieri, S. (1988). In vivo rooting of gf 655-2 peach rootstock and kiwi cv. "Hayward" Microcuttings. Acta Horticul. 227, 500-503.

15. González, O. S. y Silva, J. J. (1999). Empleo de diferentes agentes gelificantes en el cultivo de tejidos vegetales. Centro Agrícola 26 (1), 84-85.

16. Jain, N. \& Babbar, S. B. (2002). Gum katira - a cheap gelling agent for plant tissue culture media. Plant Cell, Tissue and Organ Culture 71, 223-229.

17. Jain, R., Anjaiah, V. \& Babbar, S. B. (2005). Guar gum: a cheap substitute for agar in microbial culture media. Letters in Applied Microbiology 41, 345-349. 
18. Jain, R \& Babbar, S. B. (2006). Xanthan gum: an economical substitute for agar in plant tissue culture media. Plant Cellular Reproduction 25, 81-84.

19. Jain, R. \& Babbar, S. B. (2011). Evaluation of blends of alternative gelling agents with agar and development of xanthagar, a gelling mix, suitable for plant tissue media. Asian Journal of Biotechnology 3 (2), 153-164.

20. Joshi, N. \& Purohit, S. D. (2012). Optimization of Factors Influencing Shoot Multiplication During Micropropagation of Chlorophytum borivilianum Sant. Et Fernand. Proceedings of the National Academy of Sciences India - Section B: Biological Sciences 82(3), 421-429.

21. Ivanova, M. \& Staden, J. V. (2011). Influence of gelling agent and cytokinins on the control of hyperhydricity in Aloe polyphylla. Plant Cell Tissue Organ Culture 104, 13-21.

22. Kodym, A. y Zapata, F. J. (2001). Low-cost alternatives for the micropropagation of banana. Plant Cell, Tissue and Organ Culture 66, 67-71.

23. Kuria, P., Demo, P., Nyende, A. B.\& Kahangi, E. M. (2008). Cassava starch as an alternative cheap gelling agent for the in vitro micropropagation of potato (Solanum tuberosum L.). African Journal of Biotechnology 7 (3), 301-307.

24. Hernández, M., Torruco Uco, J. G., Chel, L. \& Betancur , D. (2008). Caracterización fisicoquímica de almidones de tubérculos cultivados en Yucatán, México. Ciência e Tecnologia de Alimentos 28(3), 718-726.

25. Lee Espinosa, H. E., Laguna Cerda, A., Murguia González, J., Iglesias Andreu, L., Garcia Rosas, B., Escobeldo López, D., Martines Ocampo, Y. M., Barredo Pool, F. A. \& \& Santana Buzzy, N. (2010). Un protocolo de embriogénesis somática para la regeneración y caracterización in-vitro de Laelia anceps ssp. Dawsonii. Revista Fitotecnia Mexicana 33(4), 323-332.

26. Lucyszyn, N., Quoirin, Anjos, A. \& Sierakowski, M.-R. (2005). Blends of Agar-Galactomannan for Marubakaido Apple Rootstock Shoot Proliferation. Polímeros: Ciência e Tecnologia, 15(2), 146-150.

27. Lucyszyn, N., Quoirin, M., Koehle, H.S., Reicher, F. \& Sierakowski, M.R. (2006). Agar-galactomannan blends for strawberry (Fragaria $x$ ananassa Duchesne) cv. Pelican micropropagation. Scientia Horticulturae 107, 358 364.

28. Lucyszyn, N., Quoirin, M., Ribas, L. F., Koehler, H. S. \& Sierakowski, M. R. (2006). Micropropagation of 'Durondeau' pear in modified-gelled medium. In Vitro Cellular Development Biology Plant 42, 287-290.

29. Martínez, M., Alonso, A., Osorio, F., Gallardo, F., López, H. \& Mata, M.(2009). Evaluación de diferentes fuentes de carbohidratos y medios de soporte, para la multiplicación in vitro de porta-injertos de cítricos tolerantes a la tristeza. Agronomía Tropical 59(3), 343-350.

30. Mateen, A. Hussain, S. Rehman, S. Mahmood, B. Aslam Khan, M. Rashid, A. Sohail, M. Farooq, M. \& Ahmed Shah, S. J. (2012). Suitability of various plant derived gelling agents as agar substitute in microbiological growth media. African Journal of Biotechnology 11(45), 10362-10367.
31. Mbanaso, E.N.A. (2008). Effect of multiple subcultures on Musa shoots derived from cassava starch-gelled multiplication medium during micropropagation. African Journal of Biotechnology 7 (24), 4491-4494.

32. Medina, M. A., Sepúlveda, N. I. \& Murillo, M. V. (2008). Regeneración in vitro de plantas a partir de explantes foliares del lulo chocoano, Solanum sessiliforum Dunal vía organogénesis. Revista Institucional Universidad Tecnológica del Chocó: Investigación, Biodiversidad y Desarrollo 27(1), 82-86.

33. Mengesha, A., Ayenew, B., Gebremariam, E. \& Tadesse, T. (2012). Micro-Propagation of Vanilla planifolia Using Enset (Ensete ventricosum (Welw, cheesman)) Starch as a Gelling Agent. Current Research Journal of Biological Sciences 4(4), 519-525.

34. Mohamed, M. A. H., Alsadon, A. A. \& Al Mohaidib, M. S. (2010). Corn and potato starch as an agar alternative for Solanum tuberosum micropropagation. African Journal of Biotechnology 9 (1), 012-016.

35. Moon, P. A., Litz, R. E. \& Chavez, V. M. (2004). Effect of Gelling Agent on Growth and Development of Ceratozamia hildae Somatic Embryos. The Botanical Review 70(1), 47-53.

36. Moses F. A. \& Maliro. Lameck, G. (2004). Potential of cassava flour as a gelling agent in media for plant tissue cultures. African Journal of Biotechnology 3 (4), 244-247.

37. Murashige, T. \& Skoog, F. (1962). A revised medium for rapid growth and bioassay with tobacco tissue cultures. Physiol. Plant.15, 473-497.

38. Naik, P. S. \& Sarkar, D. (2001). Sago: an alternative cheap gelling agent for potato in vitro culture. Biologia Plantarum 44(2), 293-296

39. Ocampo, F. \& Núñez, V. M. (2007). Propagación in vitro de Psidium guajaba mediante organogénesis directa a partir de segmentos nodales. Revista Corpoica - Ciencia y Tecnología Agropecuaria 8(1), 22-27.

40. Ozel, C. A., Khawar, K.A. \& Arslan, O. (2008). A comparison of the gelling of isubgol, agar and gelrite on in vitro shoot regeneration and rooting of variety Samsun of tobacco (Nicotiana tabacum L.). Scientia Horticulturae $117,174-181$.

41. Pacheco de Delahaye, E. \& Techeira, N. (2009). Propiedades químicas y funcionales del almidón nativo y modificado de ñame (Dioscorea alata). Interciencia 34(4), 280-285.

42. Pasquel, A. (2001). Gomas: Una Aproximación A La Industria De Alimentos. Revista Amazónica de Investigación Alimentaria 1(1), 1- 8.

43. Rodríguez, H. \& Hechevarría, I. (2006) Gel de Aloe vera y harina de sagú como soporte sólido de medio de cultivo para plantas medicinales. Revista Cubana Plantas Medicinales 11(1), 1-5.

44. Romay, G., Matheus, J., Gerlts, A., Rueda, R. \& Santana, M.A. (2006). Almidón modificado de yuca como sustituto económico del agente solidificante para medios de cultivo de tejidos vegetales. Interciencia 3 (009), 686-689. 
45. Saglam, S. \& Cifici, C.Y. (2010). Effects of Agar and Isubgol on Adventitous Shoot Regeneration of Woad (Isatis tinctoria). International Journal Of Agriculture \& Biology 12 (2), 281-285.

46. Salinas, Y., Pérez, P., Castillo, J. \& Álvarez, L. A. (2003). Relación amilosa amilopectina en el almidón de harina nixtamalizada de maíz y su efecto en la calidad de la tortilla. Revista Fitotecnia Mexicana 26(002), 115-121.

47. Santos, D. (2008). Propagación in vitro de orquídeas, usando medios de cultivo, soportes y sustratos de bajo costo. (Tesis pregrado) Trabajo presentado para optar al título de biólogo, en la universidad Michoacana de San Nicolás de Hidalgo.

48. Sharifi, A., Moshtaghi, N. \& Bagheri, A. (2010). Agar alternatives for micropropagation of African violet (Saintpaulia ionantha). African Journal of Biotechnology 9 (54), 9199-9203.

49. Singh, B. \& Kaur, A. (2011). Comparison of Agar and Gum Karaya as Gelling Agent for in vitro Regeneration of Rough Lemon (Citrus jambhiri Lush.) Plantlets from Nodal Explants. J. Crop Sci. BThe Korean Society of Crop Science 14 (4), 297-303.
50. Tsay, H. S., Lee,c. Y., Agrawal, D.C. \& Basker, S. (2006). Influence of ventilation closure, gelling agent and explant type on shoot bud proliferation and hyperhydricity in Scrophularia yoshimurae - a medicinal plant. In Vitro Cellular Development Biology Plant 42, 445-449.

51. Van Ark, H.F., Zaal, M.A.C.M., Creemers-Molenaar, J. \&Van der Valk, P. (1991).Improvement of the tissue culture response of seed-derived callus cultures of $P o a$ pratensis L.: Effect of gelling agent and abscisic acid. Plant Cell, Tissue and Organ Culture 27, 275-280.

52. Wetzstein, H.Y., Kim, C. \& Sommer, H. E. (1994). Vessel Volume, Gelling Agent, and Basal Salts Affect pH and Gel Strength of Autoclave Tissue Culture Media. Horticulture Science 29(6):683-685.

53. Wu, Y., Geng, F., Chang, P. R., Yu, A. \& Ma, X. (2009). Effect of agar on the microstructure and performance of potato starch film. Carbohydrate Polymers 76, 299-304.

54. Zimmerman, R. H., Bhardwaj, S.V. y Fordham, M. I. (1995). Use of starch-gelled medium for tissue culture of some fruit crops. Plant Cell tissue and Organ Culture 43: 207-213. 